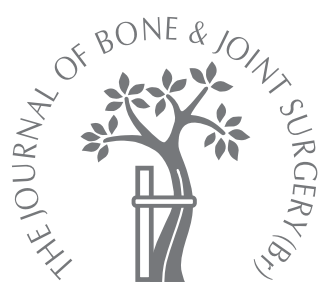

Y.-H. Kim, O.-R. Kwon, J.-S. Kim

From Ewha Womans University School of Medicine, Seoul, Korea

Y.-H. Kim, MD, Professor and Director

= O.-R. Kwon, MD, Clinical

Fellow

J.-S. Kim, MD, Professor

The Joint Replacement Center

of Korea

Ewha Womans University School of Medicine Mok Dong Hospital, 911-1, MokDong, YangChun-Gu, Seoul 158-70,

Korea.

Correspondence should be sent to Professor Y.-H. Kim; e-mail: younghookim@ewha.ac.kr

(C)2009 British Editorial Society of Bone and Joint Surgery doi:10.1302/0301-620X.91B3. $21817 \$ 2.00$

$J$ Bone Joint Surg [Br] 2009;91-B:316-20. Received 23 September 2008; Accepted after revision 6 November 2008

\title{
Is one-stage bilateral sequential total hip replacement as safe as unilateral total hip replacement?
}

We investigated whether simultaneous bilateral sequential total hip replacement (THR) would increase the rate of mortality and complications compared with unilateral THR in both low- and high-risk groups of patients.

We enrolled 978 patients with bilateral and 1666 with unilateral THR in the study. There were no significant pre-operative differences between the groups in regard to age, gender, body mass index, diagnosis, comorbidity as assessed by the grading of the American Society of Anesthesiologists (ASA), the type of prosthesis and the duration of follow-up. The mean follow-up was for $\mathbf{1 0 . 5}$ years (5 to 13) in the bilateral THR group and 9.8 years (5 to 14) in the unilateral group.

The peri-operative mortality rate of patients who had simultaneous bilateral THR $(0.31 \%$, three of 978 patients) was similar to that of patients with unilateral THR $(0.18 \%$, three of 1666 patients). The peri-operative mortality rate of patients in the bilateral group was similar in high risk and low risk patients $(0.70 \%$, two of 285 patients vs $0.14 \%$, one of 693 patients) and this was also true in the unilateral THR group $(0.40 \%$, two of 500 patients vs $\mathbf{0 . 0 9 \%}$, one of 1166 patients). Patients with bilateral THR required more blood transfusions and a longer hospital stay than those in the unilateral THR group. There was no significant difference ( $p=0.32$ ) in the overall number of complications between the groups. This was also true for the low-risk $(p=0.81)$ vs high-risk $(p=0.631)$ patients.

Our findings confirm that simultaneous sequential bilateral THR is a safe option for patients who are considered to be either high or low risk according to the ASA classification.

Bilateral simultaneous total hip replacement (THR) has the potential advantages of one operative intervention with reduction in cost and total rehabilitation time. ${ }^{1-3}$ However, these must be weighed against the potential increased risk of peri-operative complications. ${ }^{3-7}$ Some studies report a higher incidence of medical and surgical complications after this procedure compared with unilateral or staged bilateral THR, ${ }^{8}$ whereas others have refuted these findings and shown acceptable safety for simultaneous bilateral THR. ${ }^{7-10}$

The risks associated with THR are heavily influenced by the patient's general health, ${ }^{8}$ which is generally quantified by the classification of the American Society of Anesthesiologists (ASA). ${ }^{11}$ Most clinical studies have determined the safety of simultaneous bilateral THR in the low-risk (ASA 1 and 2) patient subgroups. ${ }^{1-10}$ It may be argued that an increased risk of complications in simultaneous bilateral THR in patients with increased comorbidity (ASA 3 and 4) is only a concern if the procedure on both hips is truly carried out simultaneously and that staging during the same period of anaesthesia does not involve higher risks if the actual interventions occur sequentially.

We therefore investigated whether simultaneous bilateral THR performed sequentially during the same anaesthetic session in patients with a variety of ASA scores would increase the perioperative risk compared with that in unilateral THR. We wished to determine the following: 1) whether the peri-operative mortality rate of patients who underwent simultaneous bilateral sequential THR would be increased compared with that in unilateral THR; 2) whether the peri-operative mortality rate of patients at high risk (ASA score of 3 or 4) would be increased compared with that of patients at low-risk (ASA score of 1 or 2 ), in both simultaneous bilateral sequential and unilateral THR; 3) whether the transfusion requirements would be increased in the patients who had simultaneous bilateral sequential THR; 4) whether the incidence of complications and the duration of hospital stay 
Table I. Clinical details of the patients

\begin{tabular}{|c|c|c|c|}
\hline Parameter & Bilateral THR & Unilateral THR & p-value \\
\hline Number of patients (hips) & $978 \quad(1956)$ & $1666 \quad(1666)$ & - \\
\hline Mean age in years (range) & $63.4(20$ to 85$)$ & 64.9 (18 to 90$)$ & $0.121^{\S}$ \\
\hline Gender & & & \\
\hline $\mathrm{M}: \mathrm{F}$ & $693: 285$ & $916: 750$ & $0.15^{* *}$ \\
\hline Mean height in $\mathrm{cm}$ (range) & 164.2 (140 to 184$)$ & $162.7(147$ to 187$)$ & $0.17^{\S}$ \\
\hline Mean weight in kg (range) & 63.6 (48 to 111$)$ & 62.8 (49 to 113 ) & $0.13^{\S}$ \\
\hline Mean body mass index in $\mathrm{kg} / \mathrm{m}^{2}$ (range) & $28.4(23$ to 38$)$ & 28.1 (21 to 37$)$ & $0.684^{\S}$ \\
\hline $\mathrm{ASA}^{\dagger}$ classification (\%) & & & \\
\hline 1 & 195 (19.9) & $366(22.0)$ & $0.59^{* *}$ \\
\hline 2 & $498(50.9)$ & $800(48.0)$ & $0.51^{* *}$ \\
\hline 3 & $147(15.1)$ & $266(16.0)$ & $0.48^{* *}$ \\
\hline 4 & $138(14.1)$ & $234(14.0)$ & $0.41^{* *}$ \\
\hline Diagnosis, number of patients (\%) & & & \\
\hline Osteonecrosis & $440(45.0)$ & $759(45.6)$ & - \\
\hline Osteoarthritis & $388(39.7)$ & $693(41.6)$ & - \\
\hline Fracture of the femoral neck & - & $42(2.5)$ & - \\
\hline Ankylosing spondylitis & $60(6.1)$ & - & - \\
\hline Rheumatoid arthritis & $39(3.9)$ & $20(1.2)$ & - \\
\hline Multiple epiphyseal dysplasia & $24(2.5)$ & - & - \\
\hline Congenital cova vara & $21(2.1)$ & - & - \\
\hline Childhood pyogenic arthritis & $6(0.6)$ & $92(5.5)$ & - \\
\hline Post-traumatic arthritis & - & $60(3.6)$ & - \\
\hline Type of prosthesis, patients (hips) & & & \\
\hline $\begin{array}{l}\text { Cementless Profile femoral component (DePuy, Leeds, UK) with cementless } \\
\text { Duraloc } 100 \text { or } 1200 \text { series acetabular component (DePuy, Warsaw, Indiana) }\end{array}$ & $603(1206)$ & $1006(1006)$ & $0.203^{* *}$ \\
\hline $\begin{array}{l}\text { Cementless IPS }{ }^{\ddagger} \text { femoral component with cementless Duraloc option acetabular } \\
\text { component (DePuy, Leeds, UK) }\end{array}$ & $375(750)$ & $660(660)$ & $0.212^{* *}$ \\
\hline Length of stay in hospital (days) & 14 (9 to 16$)$ & $9(7$ to 14$)$ & $0.124^{\S}$ \\
\hline Mean duration of follow-up in years (range) & $10.5(5$ to 13$)$ & $9.8(5$ to 14$)$ & $0.545^{\S}$ \\
\hline * THR, total hip replacement & & & \\
\hline † ASA, American Society of Anesthesiologists & & & \\
\hline ‡ immediate post-operative stability stem & & & \\
\hline$\S$ independent $t$-test & & & \\
\hline ** chi-squared test & & & \\
\hline
\end{tabular}

would be increased in the patients with bilateral simultaneous sequential THR; and 5) whether the clinical results and survival rate of the implant in both bilateral and unilateral THR would be similar in the intermediate to long-term follow-up.

\section{Patients and Methods}

We identified all patients who had simultaneous bilateral sequential and unilateral THR by one surgeon between 1994 and 2002. We routinely perform simultaneous bilateral sequential THR at our institute unless patients have serious life-threatening disease, in order to reduce the hospital stay, the medical cost and the total rehabilitation time. Between January 1994 and January 2002 we enrolled 978 consecutive patients admitted for bilateral THR and 1666 consecutive patients admitted for unilateral THR in our study. The exclusion criteria included medical instability and patients over 80 years of age. The two groups had similar age, gender, height, weight, body mass index, diagnosis, pre-operative ASA classification, type of prosthesis and mean follow-up (Table I). The internal review board of our hospital approved the study protocol. Informed consent was obtained from all patients.

All patients in both groups were evaluated preoperatively by an internist and anaesthetist to exclude those with life-threatening disease. For medically stable patients simultaneous bilateral sequential THR was generally performed, but if at the pre-operative assessment it was concluded that the patient was not stable enough to undergo this, they had a unilateral procedure on the more symptomatic side and returned for THR on the contralateral side, at a later date. This affected 21 patients who were not included in the study.

The fitness of the patients was categorised with low risk (ASA grades 1 and 2) and high risk (ASA grades 3 and 4). All patients underwent cementless THR. 
We recorded the operating time from the skin incision to closure and the blood loss at operation was assessed by weighing the swabs, calculating the amount of contained blood and adding this to the amount obtained by suction drainage from the operation site. We noted the amount of isotonic saline administered during the operation and the requirements for blood transfusion during and after the operation. Major and minor those were listed, together with the length of stay in hospital. Major complications were defined as these which prolonged the hospital stay by more than five days compared with the mean hospital stay, or a these requiring re-operation. All others were considered to be minor. Fat-embolism syndrome was defined using Gurd's criteria. ${ }^{12}$

Clinical and radiological follow-up was undertaken at six weeks, three and six months, one year after the operation and then yearly thereafter. The Harris hip score ${ }^{13}$ (HHS) was determined pre-operatively and at each followup examination by ORK. All the patients were evaluated for deep-vein thrombosis (DVT) with simultaneous bilateral venography or with unilateral venography on either the fifth or the sixth post-operative days. Because the prevalence of DVT and pulmonary embolism in this ethnic group of patients in the absence of any thromboprophylaxis has been reported to be low, ${ }^{14-16}$ we used no chemical or mechanical prophylaxis for our patients.

We undertook a sample size calculation, noting that in one clinical study comparing simultaneous bilateral with unilateral THR, the one-year mortality rates were found to be $1.6 \%$ and $0.7 \%$, respectively. ${ }^{8}$ Because unilateral THR is performed more often than simultaneous bilateral THR, we anticipated that we would identify almost twice as many patients treated unilaterally as those managed bilaterally over a given period. Therefore to achieve $80 \%$ power, with a two-sided type- 1 error of 0.05 , estimated one-year mortality rates of $0.7 \%$ for the unilaterally-treated and $1.6 \%$ for the bilaterally-treated and a study population with twice as many unilaterally-treated as bilaterally-treated patients, 1600 patients treated by unilateral and 950 by bilateral THR were required.

Statistical analysis. This was undertaken using SPSS for Windows version 14 (SPSS Inc., Chicago, Illinois) with the use of analysis of variance (ANOVA) for continuous variables and the chi-squared and Fisher's exact tests for dichotomous variables. The level of significance was taken as $\mathrm{p} \leq 0.05$ for both groups. The Kaplan-Meier method ${ }^{17}$ was used in the analysis of the failure-free rate with Greenwood's formula ${ }^{18}$ used to calculate the $95 \%$ confidence interval (CI) of the failure-free rate at a certain time point.

\section{Results}

The peri-operative mortality rate of patients who had simultaneous bilateral sequential THR was similar to that of patients with unilateral THR. Of the 978 patients who had bilateral sequential THR under the same anaesthetic, three $(0.31 \%)$ died from fat embolism three days after oper- ation. Three of 1666 patients $(0.18 \%)$ who had unilateral THR died within one week after the operation from myocardial infarction in two patients and fat-embolism in one. This difference was not significant (Fisher's exact test, $\mathrm{p}=0.73$ ).

The peri-operative mortality rate was found to be similar irrespective of whether patients were stratified as high or low risk in both the bilateral and unilateral groups. One of 693 patients $(0.14 \%)$ at low risk died in the bilateral group and one of 1166 patients at low risk $(0.86 \%)$ in the unilateral THR group. This difference was not significant (Fisher's exact test, $\mathrm{p}=0.99)$. Two of 285 patients $(0.70 \%$ ) at high risk died in the bilateral group and two of 500 patients $(0.40 \%)$ at high risk in the unilateral group. This difference was not significant (Fisher's exact test, $\mathrm{p}=0.89$ ).

Patients who had bilateral THR required more (independent $t$-test, $\mathrm{p}<0.001)$ blood transfusions than those in the unilateral group (4.3 units (SD 1.2) versus 1.1 units (SD 0.7), respectively) with 645 of the 978 patients $(66 \%)$ in the bilateral group and 167 of those $1666(10 \%)$ in the unilateral group receiving allogenic blood. Patients who had bilateral THR also had more peri-operative fluid replacement (independent $t$-test, $\mathrm{p}<0.001$ ) than those in the unilateral group (mean $3835 \mathrm{ml}$ (SD 822) versus mean $1668 \mathrm{ml}$ (SD 491), respectively).

Assessment of the overall number of major and minor complications showed no significant difference (chi-squared test, $\mathrm{p}=0.32$ ) between bilateral and unilateral THR (Table II). This remained true when the analysis was repeated for the low-risk (Fisher's exact test, $\mathrm{p}=0.81$ ) and high-risk (Fisher's exact test, $\mathrm{p}=0.63$ ) patients in both groups (Table III). In the bilateral group of ASA grade 1 and 2, 39 hips $(6 \%)$ were associated with the development of DVT. This compared with 82 hips in 1166 patients (7\%) in the ASA 1 and 2 unilateral THR group. All DVTs were confirmed by a positive venogram. This difference was not significant (chi-squared test, $\mathrm{p}=0.10$ ). For the patients in ASA grades 3 and 4, 21 of 285 patients $(7.4 \%)$ were associated with DVT in the bilateral group compared with 40 of 500 patients $(8.0 \%)$ in the unilateral group. No case of postoperative pulmonary embolism as a complication of DVT or fat-embolism syndrome was noted in any patient in either group. The mean length of hospital stay was three to five days longer in the bilateral than in the unilateral group.

The mean follow-up in the bilateral group was for 10.5 years ( 5 to 13 ) and for 9.8 years ( 5 to 14 ) in the unilateral group. The mean pre-operative HHS was 42 points (15 to 54 ) in the bilateral group and 43 points (16 to 57 ) in the unilateral group. The mean hip score at final followup was 94 points (68 to 100) in the bilateral and 96 points (65 to 100 ) in the unilateral group. These differences were not significant (independent $t$-test, $\mathrm{p}=0.65$ ). There were no significant differences (chi-squared test, $\mathrm{p}=0.823$ ) in revision rates in the bilateral or unilateral THR groups. Of 1956 hips in the bilateral group, 60 (3.1\%) had revision of both components for aseptic loosening compared with 50 of 1666 hips $(3.0 \%)$ in the unilateral THR group. 
Table II. Incidence of major and minor complications in the cohort

\begin{tabular}{|c|c|c|c|}
\hline \multirow[b]{2}{*}{ Complications } & \multirow{2}{*}{$\frac{\text { Bilateral THR }{ }^{*}(\mathrm{n}=978)}{\text { Number }(\%)}$} & \multirow{2}{*}{$\frac{\text { Unilateral THR }(\mathrm{n}=1666)}{\text { Number }(\%)}$} & \multirow[b]{2}{*}{ p-value } \\
\hline & & & \\
\hline \multicolumn{4}{|l|}{ Major } \\
\hline Death (caused by myocardial infarction) & $0(0)$ & $2(0.12)$ & $0.625^{\dagger}$ \\
\hline Death (caused by fat embolism) & $3(0.31)$ & $1(0.06)$ & $0.738^{\dagger}$ \\
\hline Congestive heart failure & $3(0.3)$ & $2(0.1)$ & $0.325^{\dagger}$ \\
\hline Pneumonia & $3(0.3)$ & $2(0.1)$ & $0.325^{\dagger}$ \\
\hline Cerebrovascular accident & $3(0.3)$ & $0(0.0)$ & $0.315^{\dagger}$ \\
\hline Deep wound infection & $9(0.9)$ & $4(0.2)$ & $0.318^{\dagger}$ \\
\hline Total major complications & $21(2.2)$ & $11(0.7)$ & $0.727^{\ddagger}$ \\
\hline \multicolumn{4}{|l|}{ Minor } \\
\hline Preventricular ventricular contraction (PVC) & $3(0.3)$ & $6(0.4)$ & 0.738 \\
\hline Hypertension & $15(1.5)$ & $22(1.3)$ & 0.319 \\
\hline Respiratory depression & $3(0.3)$ & $6(0.4)$ & 0.738 \\
\hline Shortness of breath & $15(1.5)$ & $8(0.5)$ & 0.812 \\
\hline lleus & $36(3.7)$ & $10(0.6)$ & 0.091 \\
\hline Urinary-track infection & $75(7.7)$ & $70(4.2)$ & 0.153 \\
\hline Thrombocytopenia & $6(0.6)$ & $2(0.1)$ & 0.316 \\
\hline Confusion & $6(0.6)$ & $10(0.6)$ & 1.000 \\
\hline Superficial wound infection & $6(0.6)$ & $2(0.1)$ & 0.153 \\
\hline Sciatic nerve palsy & $6(0.6)$ & $6(0.4)$ & 0.731 \\
\hline Dislocated hip & $33(3.4)$ & $32(1.9)$ & 0.698 \\
\hline Deep-vein thrombosis & $6.0(6.1)$ & $122(7.3)$ & $0.101^{\ddagger}$ \\
\hline Total minor complications & $264(27)$ & $296(17.8)$ & 0.136 \\
\hline
\end{tabular}

Table III. Number of patients with complications according to ASA* classification by number and percentage

\begin{tabular}{|c|c|c|c|c|}
\hline ASA classification & Death & Major & Minor & p-value \\
\hline \multicolumn{5}{|c|}{ Grades 1 and 2 (low risk) (\%) } \\
\hline Bilateral & $1(0.1)$ & $6(0.9)$ & $129(18.6)$ & $0.81^{\dagger}$ \\
\hline Unilateral & $1(0.06)$ & $4(0.3)$ & $100(8.6)$ & \\
\hline \multicolumn{5}{|c|}{ Grades 3 and 4 (high risk) (\%) } \\
\hline Bilateral & $2(0.7)$ & $12(4.2)$ & 75 (26.3) & $0.63^{\dagger}$ \\
\hline Unilateral & $2(0.4)$ & $4(0.8)$ & $74(14.8)$ & \\
\hline
\end{tabular}

* ASA, American Society of Anesthesiologists

$\dagger$, Mantel-Haenszel chi-squared test

Kaplan-Meier survival analysis, with revision as the endpoint for failure, revealed a rate of survival at ten years of both the acetabular and femoral components of $97 \%$ (95\% CI 95 to 100) in both groups.

\section{Discussion}

There is very little information in the literature regarding the peri-operative mortality of patients who have simultaneous bilateral sequential THR. ${ }^{7-10,19-21}$ One clinical study reported that 14 of 450 patients $(3.1 \%)$ in the simultaneous bilateral THR group and 18 of 450 patients $(4.0 \%)$ in the unilateral THR group died within the first post-operative year. ${ }^{8}$ Many other studies have also reported no statistically significant differences in mortality rates between patients with bilateral and unilateral THRs. ${ }^{7,9,10,19-22}$ In our study, the mortality rate was
$0.31 \%$ in the bilateral and $0.18 \%$ in the unilateral group corroborating these published results. ${ }^{7-10,19-21}$ If, however, there was a difference in the mortality rate between the two groups, the number of patients in our study would probably have been too low to detect it. It is possible that a type-II error may have occurred because of sample size, which was less than sufficient. Because of the very low mortality after THR in general, an extremely larger, perhaps impractical, number of patients would be required to avoid the possibility of such an error. ${ }^{23}$

One clinical study suggested that the ASA classification was the only independent predictor of complications and fat embolism after simultaneous bilateral THR. ${ }^{21}$ Although the authors concluded that simultaneous bilateral THR had an acceptable peri-operative risk for patients in ASA class 1 or 2 physical status (low risk), they did not perform simultaneous 
bilateral THR in patients in ASA class 3 or 4 (high risk). Another study supported the finding that simultaneous bilateral THR is a safe procedure with an acceptably low mortality rate in a select group of healthy and young low risk patients. ${ }^{20}$ By contrast, the results of other series have suggested that simultaneous bilateral THR is equally safe whether performed in low-risk (ASA 1 and 2) and high-risk (ASA 3 and 4) patients. ${ }^{9}$ We agree with the latter findings.

Many authors have found that the blood loss and transfusion requirements were significantly higher in patients undergoing simultaneous bilateral THR than in those who had a two-stage or unilateral THR. ${ }^{10,19,24}$ On the other hand, one study reported that, based on a calculation per surgicallytreated hip, patients who had simultaneous bilateral THR had a similar proportion of blood transfusions, but more patients received allogenic blood. ${ }^{21}$ In our series, patients who had simultaneous bilateral THR required more transfused allogenic blood and a longer hospital stay.

A few studies have shown a significant difference in the overall number of complications in simultaneous bilateral THR ${ }^{8,21}$ However, others have found no significant difference in the number of complications and in the number of deaths in bilateral and unilateral THR groups. ${ }^{1,910,19,20,22}$ One study also reported that the number of complications was not significantly different $(\mathrm{p}=0.99)$ between low- and high-risk patients. ${ }^{24}$ Our results revealed no significant difference in the number of complications and the number of deaths between two groups. This was also true for the subgroups of low-risk and high-risk patients.

In early publications, a higher incidence of pulmonary embolism $^{6,22}$ and increased morbidity ${ }^{6}$ were found in patients who had simultaneous bilateral THR. It can be deduced that patients with concomitant cardiopulmonary conditions may not be good candidates for simultaneous bilateral THR, but we believe that advances in anaesthesia and in operating techniques, intensive rehabilitation, and early mobilisation of patients post-operatively have led to a decrease in complications after simultaneous bilateral THR.

In our series, the revision rate did not differ between bilateral and unilateral THR or between low- and high-risk groups which reflects the findings of a previous report. ${ }^{6}$

Our study had some limitations. All the patients had cementless THR in a large-volume centre by a surgeon specialising in joint reconstruction. This may have limited the applicability of the findings to some extent. In addition, it was possible that a type-II error may have occurred because of insufficient sample size. Due to the small incidence of mortality after THR in general, an extremely large, and perhaps impractical, number of patients would be required to avoid the possibility of such an error.

No benefits in any form have been received or will be received from a commercial party related directly or indirectly to the subject of this article.

\section{References}

1. Eggli S, Huckell CB, Ganz R. Bilateral total hip arthroplasty one stage versus two stage procedure. Clin Orthop 1996;328:108-18.

2. Lorenze M, Huo MH, Zatorski LE, Keggi KJ. A comparison of the cost effectiveness of one-stage versus two-stage bilateral total hip replacement. Orthopedics 1998;21:1249-52.

3. Reuben JD, Meyers SJ, Cox DD, et al. Cost comparison between bilateral simultaneous, staged, and unilateral total joint arthroplasty. J Arthroplasty 1998;13:172-9.

4. Macaulay W, Salvati EA, Sculco TP, Pellicci PM. Single-stage bilateral total hip arthroplasty. J Am Acad Orthop Surg 2002;10:217-21.

5. Marshall PD, Douglas DL, Henry L. Fatal pulmonary fat embolism during total hip replacement due to high-pressure cementing techniques in an osteoporotic femur. $\mathrm{Br}$ J Clin Pract 1991;45:148-9.

6. Ritter MA, Stringer EA. Bilateral total hip arthroplasty: a single procedure. Clin Orthop 1980;149:185-90

7. Salvati EA, Hughes $\mathbf{P}$, Lachiewicz $\mathbf{P}$. Bilateral total hip replacement arthroplasty in one stage. J Bone Joint Surg [Am] 1978;60-A:640-4.

8. Berend ME, Ritter MA, Harty LD, et al. Simultaneous bilateral versus unilateral total hip arthroplasty: an outcome analysis. J Arthroplasty 2005;20:421-6.

9. Alfaro-Adrian J, Bayona F, Rech JA, Murray DW. One- or two-stage bilateral total hip replacement. J Arthroplasty 1999;14:439-45.

10. Parvizi J, Pour AE, Peak EL, et al. One-stage bilateral total hip arthroplasty compared with unilateral total hip arthroplasty: a prospective study. J Arthroplasty 2006;21:26-31.

11. Dripps RD. New classification of physical status. Anesthesiology 1963;24:111-17

12. Gurd AR. Fat embolism: an aid to diagnosis. J Bone Joint Surg [Br] 1970;52-B:732-7.

13. Harris WH. Traumatic arthritis of the hip after dislocation and acetabular fractures: treatment by mold arthroplasty: an end-result study using a new method of result evaluation. J Bone Joint Surg [Am] 1969:51-A:737-55.

14. Kim YH, Suh JS. Low incidence of deep-vein thrombosis after cementless total hip replacement. J Bone Joint Surg [Am] 1988;70-A:878-82.

15. Kim YH, Oh SH, Kim JS. Incidence and natural history of deep vein thrombosis after total hip arthroplasty: a prospective and randomized clinical trial. J Bone Joint Surg [Br] 2003;85-B:661-5.

16. Kim YH, Kim JS. The 2007 John Charnley Award: factors leading to low prevalence of DVT and pulmonary embolism after THA: analysis of genetic and prothrombotic factors. Clin Orthop 2007;465:33-9.

17. Kaplan EL, Meier P. Nonparametric estimation from incomplete observation. J Am Stat Assoc 1958;53:457-81.

18. Greenwood M. A report on the natural duration of cancer: Rep Publ HIth Med Subj 1926; Stationary Office, 1926:1-26. HMSO 33:1-26:33.

19. Bhan S, Pankaj A, Malhotra R. One- or two-stage bilateral total hip arthroplasty: a prospective, randomized, controlled study in an Asian population. J Bone Joint Surg [Br] 2006;88-B:298-303.

20. Tarity TD, Herz AL, Parvizi J, Rothman RH. Ninety-day mortality after hip arthroplasty: a comparison between unilateral and simultaneous bilateral procedures. $J$ Arthroplasty 2006;21:60-4.

21. Swanson KC, Valle AG, Salvati EA, Sculco TP, Bottner F. Perioperative morbidity after single-stage bilateral total hip arthroplasty: a matched control study. Clin Orthop 2006;451:140-5.

22. Bracy D, Wroblewski BM. Bilateral Charnley arthroplasty as a single procedure: a report on 400 patients. J Bone Joint Surg [Br] 1981;63-B:354-6.

23. Riffenburgh RH. Sample size required for a study. In: Riffenburgh, ed. Statistics in medicine. Amsterdam: Elsevier Academic Press; 2006:115-23.

24. Schäfer M, Elke R, Young JR, Gancs P, Kindler CH. Safety of one-stage bilateral hip and knee arthroplasties under regional anesthesia and routine anesthetic monitoring. J Bone Joint Surg [Br]2005;87-B:1134-9. 